\title{
Cornel iridoid glycoside ameliorates cognitive deficits in APP/ PS1/tau triple transgenic mice by attenuating amyloid-beta, tau hyperphosphorylation and neurotrophic dysfunction
}

\author{
Cuicui Yang, Xunjie Bao, Li Zhang, Yali Li, Lin Li, Lan Zhang \\ Department of Pharmacy, Xuanwu Hospital of Capital Medical University, Beijing Institute for Brain Disorders, Beijing Engineering Research \\ Center for Nerve System Drugs, Key Laboratory for Neurodegenerative Diseases of Ministry of Education, Beijing 100053, China \\ Contributions: (I) Conception and design: C Yang; (II) Administrative support: L Li, L Zhang; (III) Provision of study materials or patients: L Li, L \\ Zhang; (IV) Collection and assembly of data: L Zhang, Y Li; (V) Data analysis and interpretation: X Bao; (VI) Manuscript writing: All authors; (VII) \\ Final approval of manuscript: All authors. \\ Correspondence to: Lin Li. Department of Pharmacy, Xuanwu Hospital of Capital Medical University, Beijing 100053, China. Email: linlixw@126.com; \\ Lan Zhang. Department of Pharmacy, Xuanwu Hospital of Capital Medical University, Key Laboratory for Neurodegenerative Diseases of Ministry \\ of Education, 45 Chang-chun Street, Beijing 100053, China. Email: lanizhg@126.com.
}

\begin{abstract}
Background: Targeted proteinopathy is involved in creating pharmacological agents that protect against Alzheimer disease (AD). Cornel iridoid glycoside (CIG) is an effective component derived from Cornus officinalis. The present study aimed to determine the effects of CIG on $\beta$-amyloid (A $\beta$ ) and tau pathology and the underlying mechanisms in APP/PS1/tau triple transgenic $(3 \times \mathrm{Tg})$ model mice.

Methods: We intragastrically administered 16-month-old 3xTg mice with CIG (100 and $200 \mathrm{mg} / \mathrm{kg}$ ) daily for two months. Learning and memory abilities were determined using the Morris water maze (MWM) and object recognition tests (ORT). Amyloid plaques and A $\beta 40 / 42$ and the expression of related proteins in the cerebral cortex and hippocampus of mice was determined by western blotting

Results: CIG improved learning and memory impairment in 3xTg model mice, decreased amyloid plaque deposition, $A \beta 40 / 42$ and the expression of full-length amyloid precursor protein, and increased levels of ADAM-10 ( $\alpha$-secretase), neprilysin (NEP), and insulin degrading enzyme (IDE) in the brains of the model mice. CIG also reduced tau hyperphosphorylation, and elevated phosphorylation level of GSK-3 $\beta$ at Ser9 and methylation of PP2A catalytic subunit $\mathrm{C}$ in the model mice. Moreover, CIG increased the expression of nerve growth factor (NGF), brain-derived neurotrophic factor (BDNF) and phosphorylated cAMPresponsive element binding protein (p-CREB) in the brain of $3 \times \mathrm{Tg}$ mice.

Conclusions: CIG ameliorated learning and memory deficit via reducing $\mathrm{A} \beta$ content and, tau hyperphosphorylation and increasing neurotrophic factors in the brain of $3 \times \mathrm{Tg}$ mice. These results suggest that CIG may be beneficial for AD therapy.
\end{abstract}

Keywords: Cornel iridoid glycoside (CIG); Alzheimer's disease (AD); $\beta$-amyloid (A $\beta$ ); tau protein; neurotrophic factor

Submitted Dec 03, 2019. Accepted for publication Feb 05, 2020.

doi: 10.21037/atm.2020.02.138

View this article at: http://dx.doi.org/10.21037/atm.2020.02.138

\section{Introduction}

Alzheimer disease (AD) is the most prevalent of the neurodegenerative diseases affecting elderly $(1,2)$. It is characterized by a biological continuum that includes progressive decline of memory and cognition function and neuronal loss (3). $\mathrm{AD}$ is reported caused by the deposition of abnormally folded or processed proteins result in cell death (4). The two main neuropathological hallmarks 
are senile plaques which are mainly composed of compose amyloid- $\beta$ (A $\beta)$ and intracellular neurofibrillary tangles which consist of hyperphosphorylated tau $(5,6)$. A $\beta$ peptides are generated from amyloid- $\beta$ precursor protein (APP) via ordinal cuts by $\beta$-secretase (the $\beta$-site APP-cleaving enzyme 1, BACE-1) $(7,8)$. Insulin degrading enzyme (IDE) and neprilysin (NEP) are the two major A $\beta$-degrading enzyme (9). Tau is a soluble axonal microtubule-binding protein and is primarily localized in neurons and mediates synaptic structure, axonal transport and neuronal signaling pathways $(10,11)$. An imbalance between protein phosphatases and protein kinases is the principal cause of tau hyperphosphorylation. Protein phosphatase 2A (PP2A) and glycogen synthase

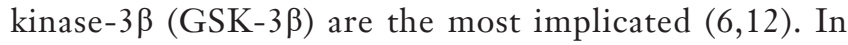
addition, reduced expression of neurotrophic factors also plays a crucial role in the pathogenesis of $\mathrm{AD}$ (13). Higher expression of neurotrophic factors slows down cognitive decline in the elderly, especially in the setting of advancing AD neuropathology (14).

We extracted the active component, cornel iridoid glycoside (CIG), from a traditional Chinese herb Cornus officinalis. Cornus officinalis has been included in the traditional Chinese medicine prescriptions for treating dementia and other age-related diseases in China for many years. Aging is the most important risk factor of $\mathrm{AD}$. We also recently showed that CIG ameliorated the cognitive impairment in senescence-accelerated mouse prone 8 (SAMP8) mice (15). Cholinergic damage plays an important role in the pathogenesis of AD. Our study revealed that CIG improved memory ability and promoted neuronal survival in fimbria-fornix transected rats which served as a cholinergic injury and AD-like model (16). Our recent studies demonstrated that CIG attenuated the hyperphosphorylation level of tau by regulating crosstalk between GSK-3 $\beta$ and PP2A in GSK $3 \beta$-activating cell model (17) and GSK3 $\beta$-transfected cell models (18). However, whether CIG could affect $A \beta$, tau and neurotrophic dysfunction in APP and tau transgenic animal model has remained unknown. Therefore, in the present study, we investigated the effects of CIG on AD-related pathology and its underlying mechanisms in APP/PS1/tau triple transgenic $(3 \times \mathrm{Tg})$ model mice.

\section{Methods}

\section{Drugs}

We extracted CIG from the sarcocarp of Cornus officinalis as described by Yao et al. (19). The purity of CIG was 70\%, in which morroniside and loganin accounted for $67 \%$ and $33 \%$, respectively, of the extract determined by RP-HPLC.

\section{Animals and drug treatment}

APP/PS1/tau triple transgenic $(3 \times \mathrm{Tg})$ mice over-expressing mutant APP (APPSWE), PS1 (PS1M146V) and tau (tauP301L) were obtained from the Institute of Laboratory Animal Sciences, Chinese Academy of Medical Sciences (Beijing, China). Wild type (WT) littermates served as ageand gender-matched controls. The mice had free access to food and water under a 12/12-h dark/light cycle and standard pathogen-free conditions throughout the study. Animal housing and all experimental procedures conformed to the requirements of the Provisions and General Recommendations of Chinese Experimental Animal Administration Legislation.

Wild-type (WT) and $3 \times \mathrm{Tg}$ mice (16 months old) were randomly assigned to the following groups: WT administered with vehicle (WT control), or CIG $100 \mathrm{mg} / \mathrm{kg}$ (WT + CIG100), and $3 \times \mathrm{Tg}$ mice treated with vehicle $(3 \times \mathrm{Tg})$, or CIG $100 \mathrm{mg} / \mathrm{kg}(3 \times \mathrm{Tg}+\mathrm{CIG} 100)$ or $200 \mathrm{mg} / \mathrm{kg}(3 \times \mathrm{Tg}$ + CIG200).

Either CIG or vehicle (distilled water) was administered to the mice via oral gavage daily for two months. Thereafter, cognitive behavioral performance was assessed using the Morris water maze (MWM) and object recognition tests (ORT). The mice were then anesthetized with $10 \%$ chloral hydrate $(4 \mathrm{~mL} / \mathrm{kg})$ and decapitated while unconscious. The brains were dissected and stored at $-80^{\circ} \mathrm{C}$.

\section{$M W M$}

Spatial learning and memory performance were tested in all experimental mice using the MWM, which consisted of a dark gray tank (diameter, $120 \mathrm{~cm}$; height, $60 \mathrm{~cm}$ ) containing water maintained at temperatures between 24 and $26^{\circ} \mathrm{C}$. An escape platform (diameter, $9.5 \mathrm{~cm}$ ) was located two centimeters below the water surface in the center of the northwest quadrant during a training period. The mice were acclimated to the platform in the pool during training day 1 , then the platform was hidden from days 2 to 5 . Each mouse underwent two training sessions daily for four consecutive days (acquisition phase). Two trials proceeded simultaneously each day for a total of six days. On the day after the last training session, the mice underwent a probe trial in which they were allowed to swim for $60 \mathrm{~s}$ to find the 
platform that had been removed from the pool. Mice were gently placed into the water facing the maze wall at one of four quadrants during each trial, then their activities were video recorded and analyzed using a computerized video system.

\section{$O R T$}

The ORT is widely used to measure recognition memory in mice (20). Mice were placed in the center of an empty $250-\mathrm{mm}^{3}$ test arena on day 1 and allowed to explore for 5 min. During the training phase, the mice were presented with two similar objects to explore for $5 \mathrm{~min}$ on day 2 . During the test phase, one of the two objects was replaced with a new object on day 3 . The arena and the objects were thoroughly cleaned with $10 \%$ ethanol to eliminate olfactory cues throughout the trial. A discrimination index (DI) was calculated as (the amount time spent exploring the novel object-the amount of time exploring the familiar object) divided by the total amount of time spent with both objects.

\section{Immunobistochemical procedure}

Mouse brains were fixed in $4 \%$ paraformaldehyde overnight, dehydrated in $30 \%$ sucrose and rapidly frozen in optimal cutting temperature compound (OCT) embedding medium. Frozen sections (thickness, $20 \mu \mathrm{m}$ ) were taken through the hippocampus and processed under free-floating conditions. The slices were subsequently mounted on glass slides and stained for amyloid plaques as follows.

Brain slices were incubated with a mouse monoclonal anti-A $\beta$ antibody (Cell Signaling Technology Inc., Danvers, MA, USA). Non-specific binding on sections for immunohistochemistry (IHC) was blocked with $5 \%$ BSA (Sigma); then, the sections were incubated with mouse monoclonal anti-A $\beta$ antibody (diluted 1:300) at $4{ }^{\circ} \mathrm{C}$ overnight, followed by goat anti-rabbit or anti-mouse secondary antibodies (diluted 1:100) at room temperature for 30 minutes. Areas of $\mathrm{A} \beta$ plaques were counted within fields of view of the same size $\left(\mu^{2}\right)$ under the microscope, and calculated using Image J software (Research Services Branch, National Institute of Mental Health, Bethesda, MD, USA).

\section{Western blotting}

Samples with equal protein concentrations were separated by sodium dodecyl sulfate-polyacrylamide gel electrophoresis (SDS-PAGE), then transferred to polyvinylidene fluoride (PVDF) membranes. Non-specific binding was blocked by incubating the membranes with $5 \%$ non-fat milk for $1 \mathrm{~h}$, then with various primary antibodies at $4{ }^{\circ} \mathrm{C}$ overnight (see below). The membranes were washed with Tris-buffered saline containing Tween 20 (TBST), then incubated for $2 \mathrm{~h}$ with goat anti-rabbit or anti-mouse secondary antibodies conjugated to horseradish peroxidase. The membranes were then rinsed three times with TBST. Protein signals were visualized using the chemiluminescence reagents in the ECL kit (Merck-Millipore, Burlington, MA, USA), and proteins were quantified by densitometric analysis using AlphaView SA gel image processing system software (ProteinSimple, San Jose, CA, USA).

The monoclonal primary antibodies used in these assays comprised rabbit anti-A $\beta$ antibody diluted 1:1,000; mouse anti-CREB antibody diluted 1:1,000 and rabbit anti-phosphorylated CREB antibody diluted 1:1,000 (Cell Signaling Technology), rabbit anti-APP antibody diluted 1:500, rabbit anti-BACE1 antibody diluted 1:10,000, rabbit anti-IDE antibody diluted 1:10,000, rabbit anti-pGSK3 $\beta$-Ser9 antibody diluted 1:1,000 and rabbit anti-NGF antibody diluted 1:1,000 (Abcam, Cambridge, UK); rabbit anti-ADAM10 antibody (diluted 1:10,000; Sigma), rabbit anti-NEP antibody diluted 1:1,000 (Merck-Millipore); rabbit anti-PP2Ac antibody diluted 1:500 and mouse antimethylated PP2Ac antibody diluted 1:100 (Santa Cruz Biotechnology Inc., Dallas TX, USA); rabbit anti-GSK-3 $\beta$ antibody diluted $1: 1,000$ and mouse anti- $\beta$-actin antibody diluted 1:1,000 (ZSGB-Biotechnology Company, Beijing, China); rabbit anti-BDNF antibody diluted 1:2,000 (Epitomics International Inc., Burlingame, CA, USA); rabbit anti-phosphorylated tau at Ser396 antibody diluted 1:1,000 and rabbit anti-phosphorylation tau at Ser44 site antibody diluted 1:1,000 (Invitrogen, Waltham, MA, USA).

\section{Statistical analysis}

Data were statistically analyzed using the Statistical Package for the Social Sciences (SPSS) 16.0 (SPSS Inc., Chicago, IL, USA). All data are expressed as means \pm the standard error of the mean (SEM). Escape latency and average swim speed in MWM tests were assessed using a repeated-measures analysis of variance (ANOVA). Differences among more than three groups were analyzed using one-way ANOVA followed by post-hoc LSD tests. Values with $\mathrm{P}<0.05$ were considered statistically significant. 

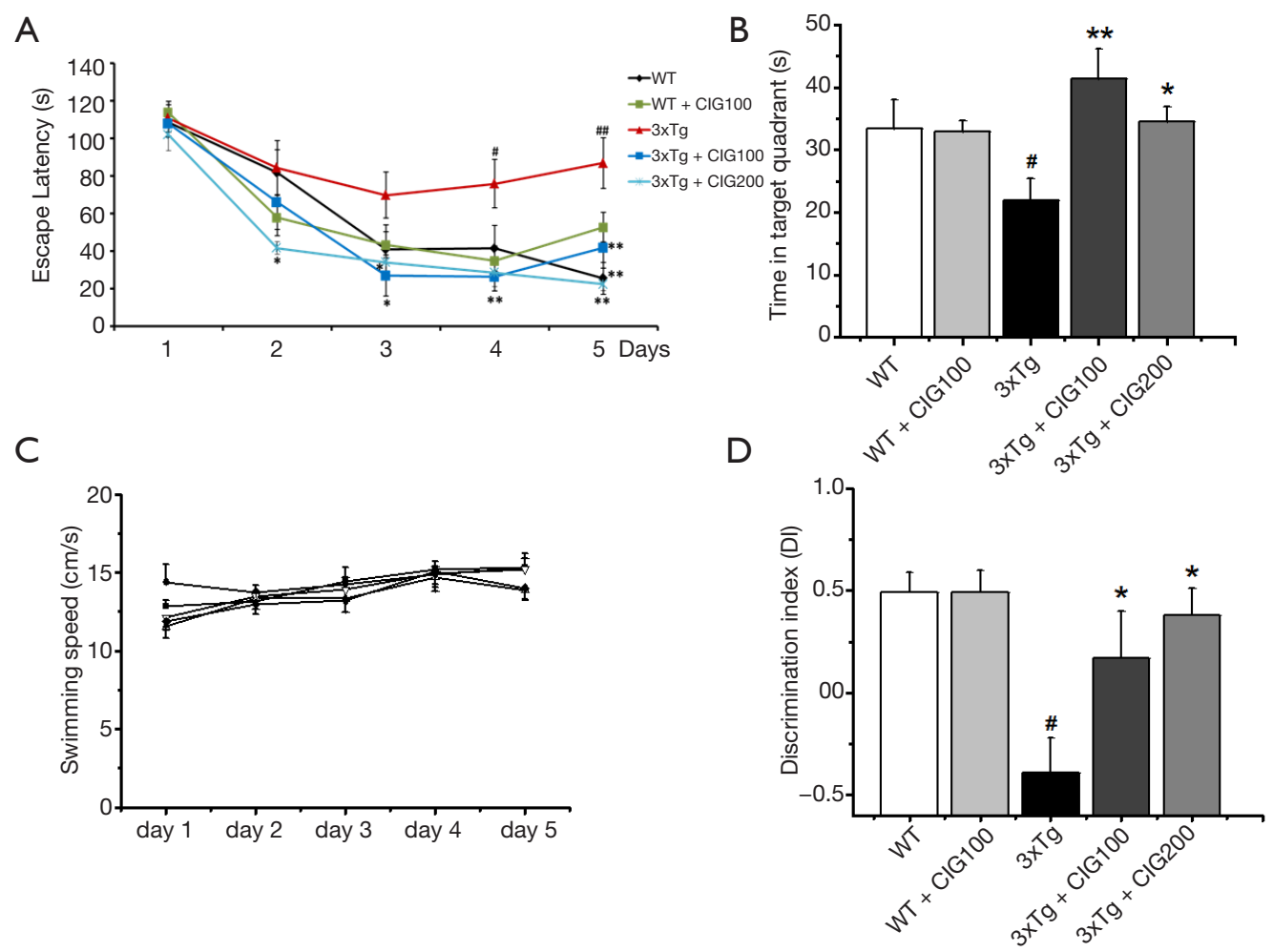

Figure $1 \mathrm{CIG}$ ameliorates learning and memory impairment in 3xTg mice. Learning and memory abilities of 18-month-old APP/PS1/ tau triple transgenic $(3 \times \mathrm{Tg})$ or wild type (WT) mice were assessed using a Morris water maze (MWM) and object recognition tests (ORT) after intragastric administration of CIG (100 and $200 \mathrm{mg} / \mathrm{kg}$ ) for two months. (A) Escape latency in MWM test. (B) Amount of time spent in target quadrant on day 6 of probe trial of MWM test. (C) Swimming speed in MWM test. (D) Discrimination index (DI) in ORT. Data are presented as means \pm SEM, $\mathrm{n}=7-9$ for each group. ${ }^{*}, \mathrm{P}<0.05,{ }^{\# \#}, \mathrm{P}<0.01,3 \times \mathrm{Tg}$ group vs. WT group; ${ }^{*}, \mathrm{P}<0.05,{ }^{* *}, \mathrm{P}<0.01, \mathrm{CIG}-$ treated groups vs. untreated $3 \times \mathrm{Tg}$ group. CIG, cornel iridoid glycoside.

\section{Results}

\section{CIG ameliorated learning and memory deficits in $3 \times T g$ mice}

We intragastrically administered CIG to 16-month-old $3 \times \mathrm{Tg}$ mice for two months, then assessed spatial learning and memory ability using the MWM. Escape latency was prolonged in $3 \times \mathrm{Tg}$ model mice compared with $\mathrm{WT}$ controls $(\mathrm{P}<0.001)$, but significantly shortened in $3 \times \mathrm{Tg}$ mice administered with 100 and $200 \mathrm{mg} / \mathrm{kg}$ CIG $(\mathrm{P}<0.001$; Figure $1 A$ ). The probe test on day 6 showed that $\mathrm{WT}$ and CIG-treated $3 \times \mathrm{Tg}$ mice spent more time swimming in the target quadrant than vehicle-treated $3 \times \mathrm{Tg}$ mice $(\mathrm{P}<0.05$ and $\mathrm{P}<0.01$; Figure $1 B)$. Swimming speed did not significantly differ among the groups (Figure 1C), which ruled out the possibility that changes in motor function affected escape latency.

Recognition memory was assessed in the mice using
ORT. Figure $1 D$ shows that the discrimination index (DI) was considerably lower in vehicle-treated $3 \times \mathrm{Tg}$, compared with WT mice $(\mathrm{P}<0.05)$, whereas the DI was significantly increased in $3 \times \mathrm{Tg}$ mice administered with 100 and $200 \mathrm{mg} / \mathrm{kg}$ CIG for two months compared with vehicletreated $3 \times \mathrm{Tg}$ mice $(\mathrm{P}<0.05)$. These results indicated that CIG improved cognitive impairment in $3 \times \mathrm{Tg}$ mice.

\section{CIG decreases amyloid plaque deposition and Aß contents in the brain of $3 \times \mathrm{Tg}$ mice}

The major components of amyloid plaques, $\beta$-amyloid 1-40 (A $\beta 40)$ and $A \beta 1-42(\mathrm{~A} \beta 42)$ accumulate within pyramidal neurons in the brains of individuals with $A D$ (21). We detected $A \beta 40$ and $A \beta 42$ expression using immunohistochemical staining. Figure 2 shows that CIG obviously decreased the characteristic abundance of $\mathrm{A} \beta 40 / 42$ in the cerebral cortex and hippocampus of $3 \times \mathrm{Tg}$ 
A

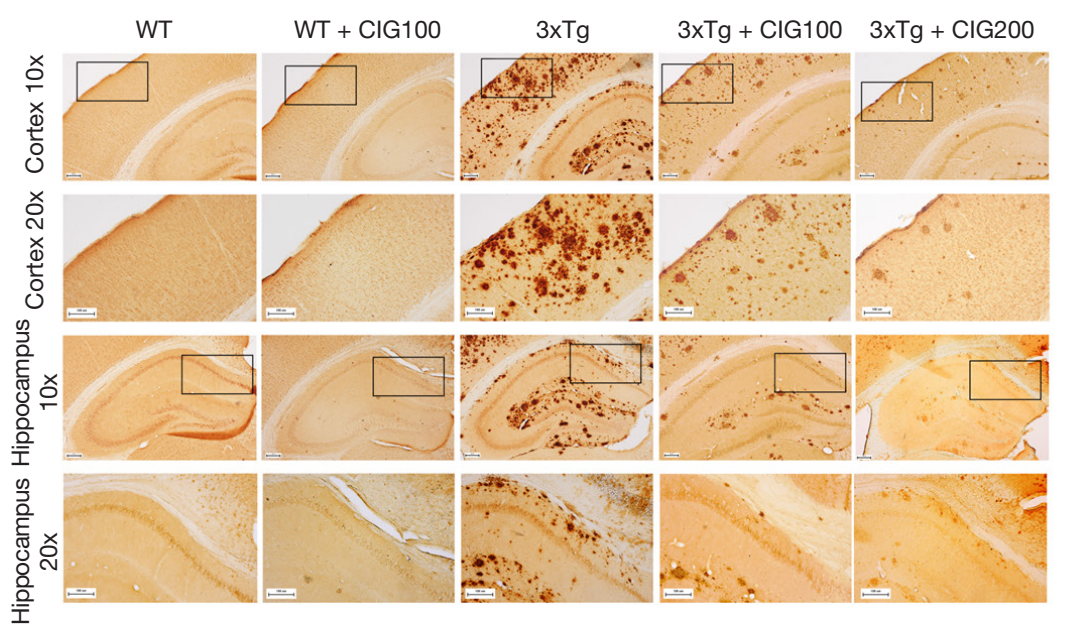

B

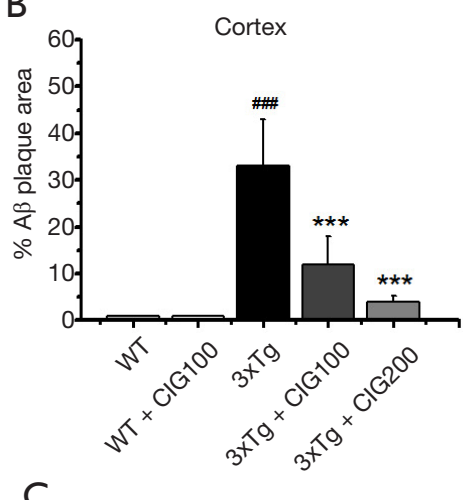

C

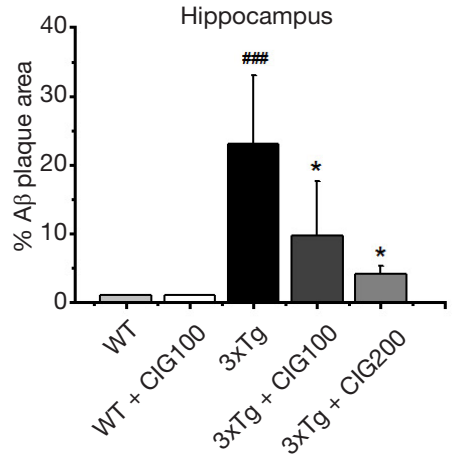

Figure 2 CIG decreases amyloid plaques and A $\beta$ deposition in the cerebral cortex and hippocampus of $3 \times \mathrm{Tg}$ mice. (A) Representative images of $\mathrm{A} \beta$ deposition in cerebral cortex and hippocampus visualized using immunohistochemistry. Scale bar $=100 \mu \mathrm{m}$. (B,C) Quantitation of ratios (\%) of $\mathrm{A} \beta$ plaque areas in cerebral cortex and hippocampus, respectively. Data are presented as means $\pm \mathrm{SEM},(\mathrm{n}=3)$. ${ }^{\# \#}, \mathrm{P}<0.001$, $3 \times$ Tg group $v s$. WT group; ${ }^{*}, \mathrm{P}<0.05,{ }^{* * *}, \mathrm{P}<0.001$, CIG-treated groups $v s .3 \times$ Tg group. CIG, cornel iridoid glycoside.

model mice $(\mathrm{P}<0.001)$.

\section{CIG reduces APP expression and increases ADAM-10 level in the brain of $3 \times \mathrm{Tg}$ mice}

To investigate the production of $\mathrm{A} \beta$ pathways, detect full-length APP (FL APP), ADAM-10 and BACE-1. Significantly more FL APP was expressed in the cerebral cortex and hippocampus of $3 \times \mathrm{Tg}$ compared with WT mice $(\mathrm{P}<0.001)$, and this was significantly decreased by CIG $(\mathrm{P}<0.05, \mathrm{P}<0.01, \mathrm{P}<0.001$; Figure $3 A, B)$. We then assessed the expression of ADAM-10 ( $\alpha$-secretase) and BACE-1 $(\beta$-secretase), that are key enzymes in non-amyloidogenic and amyloidogenic APP processing pathways, respectively. The significantly decreased expression of ADAM-10 in the cerebral cortex and hippocampus of $3 \times \mathrm{Tg}$ mice treated with vehicle $(\mathrm{P}<0.01)$, was significantly increased by CIG $(\mathrm{P}<0.001$; Figure $3 A, C)$. However, levels of BACE-1 did not significantly differ among the groups (Figure $3 A, D$ ). These results indicated that CIG decreased $\mathrm{A} \beta$ production.

\section{CIG increases the expression of NEP and IDE in the brain of $3 \times T g$ mice}

NEP and IDE are crucial enzymes that are involved in $A \beta$ (22). Western blots showed that the obviously depleted levels of NEP and IDE in the cerebral cortex and hippocampus of $3 \times \mathrm{Tg}$, compared with $\mathrm{WT}$ mice $(\mathrm{P}<0.05)$ were significantly increased by CIG $(\mathrm{P}<0.001$; Figure 4$)$, indicating that $\mathrm{CIG}$ promoted $\mathrm{A} \beta$ degradation.

\section{CIG inbibits tau byperphosphorylation in the brain of $3 \times$ Tg mice}

Figure 5 shows remarkably increased tau phosphorylation at Ser396 and Ser404 in the cerebral cortex, and obviously elevated expression of phosphorylated tau at Ser404 in the hippocampus of $3 \times \mathrm{Tg}$ mice $(\mathrm{P}<0.001$ and $\mathrm{P}<0.05)$. 


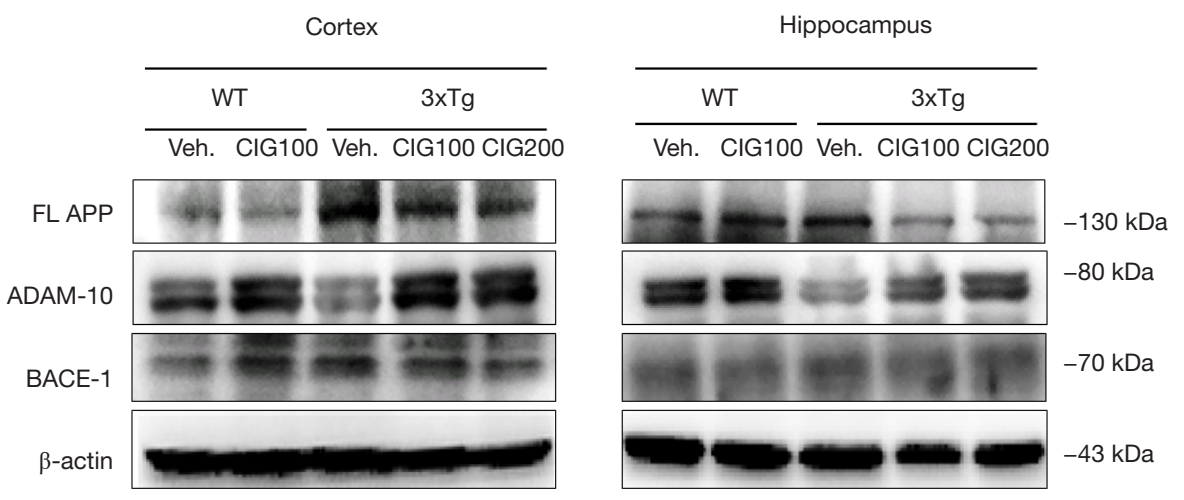

B

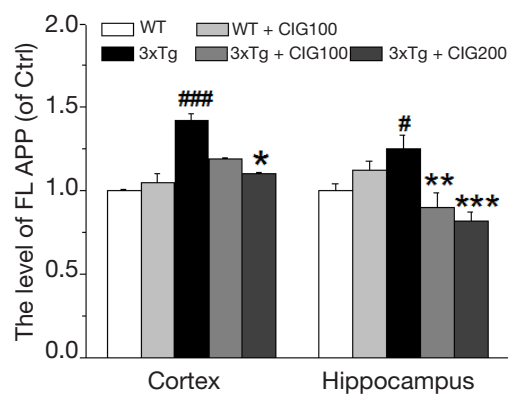

C

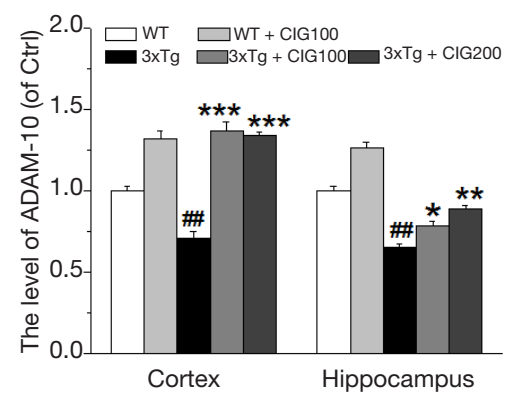

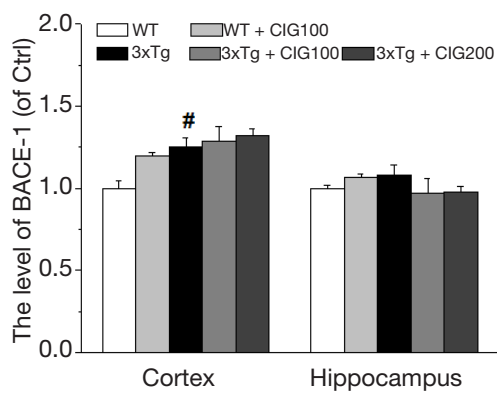

Figure 3 CIG decreases APP expression and increases ADAM-10 level in the cerebral cortex and hippocampus of $3 \times$ Tg mice (western blotting). (A) Representative western blots of full-length APP (FL APP), ADAM-10 and BACE-1. Quantitative findings of FL APP (B), ADAM-10 (C) and BACE-1 (D), respectively. Internal control was $\beta$-actin. Ratio of target protein to $\beta$-actin in W'T control group was set as 1 . Data are expressed as means $\pm \mathrm{SEM} ; \mathrm{n}=4$ per group. ${ }^{\#}, \mathrm{P}<0.05,{ }^{\# \#}, \mathrm{P}<0.01,{ }^{\# \# \#}, \mathrm{P}<0.001,3 \times \mathrm{T}$ g group vs. WT group; * $, \mathrm{P}<0.05,{ }^{* *}, \mathrm{P}<0.01,{ }^{* * *}$, $\mathrm{P}<0.001$, CIG-treated groups vs. $3 \times$ Tg group. CIG, cornel iridoid glycoside.

Tau hyperphosphorylation at Ser396 and Ser404 in the cerebral cortex and hippocampus of $3 \times \mathrm{Tg}$ mice significantly decreased by CIG $(\mathrm{P}<0.05$ and $\mathrm{P}<0.001)$. The total amounts of tau did not significantly differ among the groups.

\section{CIG regulates the activity-related modifications of $P P 2 A$ and GSK-3 $\beta$ in the brain of $3 \times T g$ mice}

Glycogen synthase kinase- $3 \beta$ (GSK-3 $\beta$ ) and protein phosphatase $2 \mathrm{~A}(\mathrm{PP} 2 \mathrm{~A})$ are the most important enzymes for phosphorylating and dephosphorylating tau protein, respectively (23). Figure 6 shows a significant decline in the expression of methylated PP2A catalytic subunit C $(\mathrm{m}-\mathrm{PP} 2 \mathrm{Ac})$ at Leu309 in the hippocampus $(\mathrm{P}<0.001)$, and a significant decrease in phosphorylated GSK-3 $\beta$ at Ser9 (p-GSK3 $\beta$-Ser9) in the cerebral cortex and hippocampus of $3 \times \mathrm{Tg}$ mice $(\mathrm{P}<0.001)$. The expression of $\mathrm{m}-\mathrm{PP} 2 \mathrm{Ac}$ and p-GSK $3 \beta-$ Ser9 in the cerebral cortex and hippocampus of
$3 \times$ Tg mice was significantly elevated by CIG $(\mathrm{P}<0.001)$, implying that CIG respectively increased and decreased PP2A and GSK-3 $\beta$ activities.

\section{CIG elevates the expression of neurotrophic factors and $p$-CREB in the brain of $3 \times T g$ mice}

Neurotrophic factors play critical roles in synaptic plasticity, neuronal development, survival and appropriate function (24). We evaluated the expression of NGF and BDNF by western blotting. Figure 7 shows decreased NGF and BDNF expression in the cerebral cortex and hippocampus of $3 \times \mathrm{Tg}$, compared with WT mice $(\mathrm{P}<0.001)$ that was significantly increased by CIG $(\mathrm{P}<0.001)$. Moreover, CREB, which is a representative downstream molecule of BDNF signaling was activated. The expression of phosphorylated CREB (p-CREB) was reduced in the hippocampus of $3 \times \mathrm{Tg}$ mice $(\mathrm{P}<0.05)$, and $C I G$ elevated $\mathrm{p}-\mathrm{CREB}$ expression in the 
A

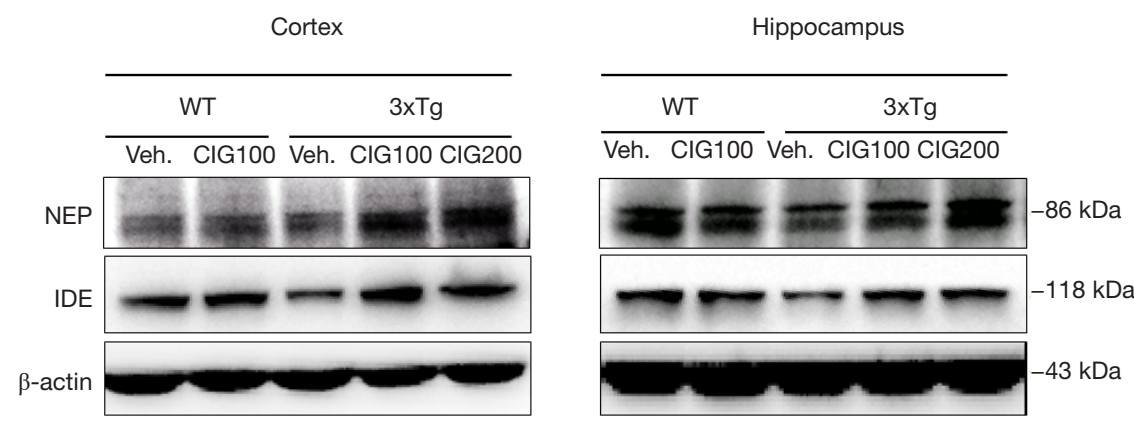

B

C
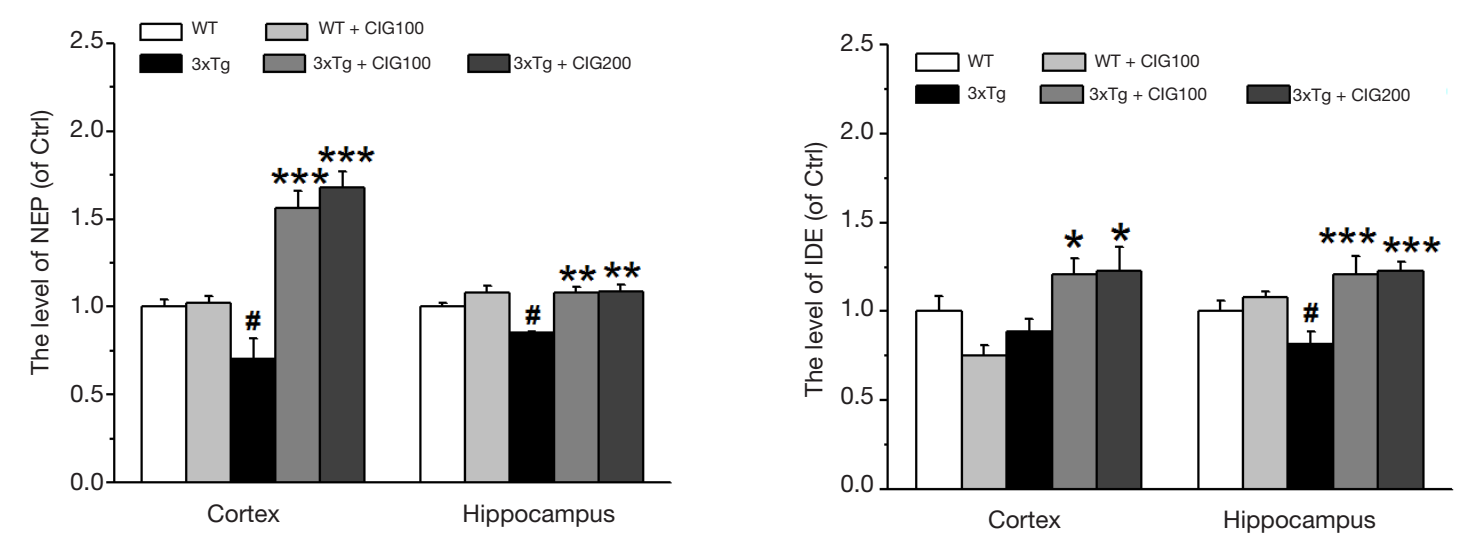

Figure 4 CIG increases the expression of NEP and IDE in the cerebral cortex and hippocampus of $3 \times \mathrm{Tg}$ mice (western blotting). (A) Representative western blots of neprilysin (NEP) and insulin degrading enzyme (IDE). Quantitative findings of NEP (B) and IDE (C). Internal control was $\beta$-actin. Ratio of target protein to $\beta$-actin in $W T$ control mice was set as 1 . Data are expressed as means $\pm S E M ; n=4$ per group. ${ }^{*}, \mathrm{P}<0.05,3 \times$ Tg group vs. WT group; ${ }^{*}, \mathrm{P}<0.05,{ }^{* *}, \mathrm{P}<0.01,{ }^{* *}, \mathrm{P}<0.001$, CIG-treated groups $v s .3 \times$ Tg group. CIG, cornel iridoid glycoside.

cerebral cortex and the hippocampus of these mice $(\mathrm{P}<0.05$, $\mathrm{P}<0.001$; Figure 7). These results suggested that CIG activated the neurotrophic factor/CREB signaling pathway.

\section{Discussion}

Our present study investigated the effects of CIG using $\mathrm{APP} / \mathrm{PS} 1 /$ tau triple transgenic $(3 \times \mathrm{Tg})$ mice which overexpressed mutant APP (APPSWE), PS1 (PS1M146V) and tau (tauP301L). The results demonstrated that CIG improved learning and memory impairment, decreased $A \beta$ content, inhibited tau hyperphosphorylation, and increased neurotrophic factors in the brain of $3 \times \mathrm{Tg}$ mice.

One of the main neuropathological hallmarks of $\mathrm{AD}$ is extracellular senile plaques formed by deposition of $A \beta$.
In our present study, 18-month-old $3 \times \mathrm{Tg}$ mice showed abundant amyloid plaques and $\mathrm{A} \beta$ plaque deposition in the brain, while CIG treatment for 2 months significantly decreased amyloid plaques and $\mathrm{A} \beta$ deposition in the hippocampus and cerebral cortex of $3 \times \mathrm{Tg}$ mice. It has been reported that $A \beta \quad 1-40$ and $A \beta$ 1-42 are neurotoxic peptides which are generated from APP through sequential proteolytic cleavages by $\beta$-secretase (BACE-1) and $\gamma$-secretase $(25,26)$. Conversely, $\alpha$-secretase (a disintegrin and metalloproteinase 10, ADAM10) cleaves APP within the eventual $A \beta$ sequence and precludes $A \beta$ generation (27). Moreover, A $\beta$ can be degraded and cleared by IDE and NEP. Maintaining a balance between the production and clearance of $A \beta$ is considered to be potential strategy for $\mathrm{AD}$ (28). $\mathrm{A} \beta$ production and increasing $\mathrm{A} \beta$ degradation 
A

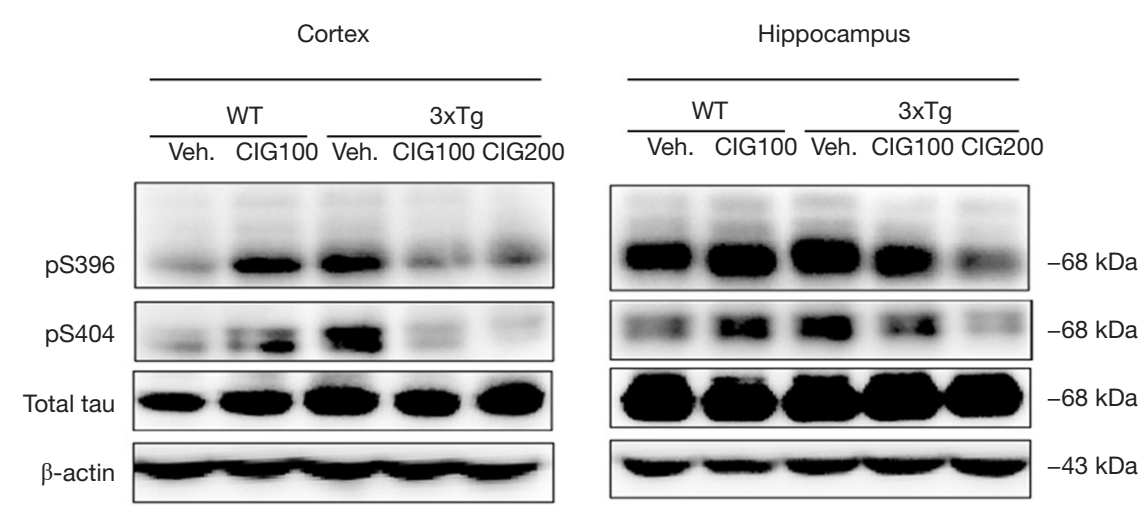

B

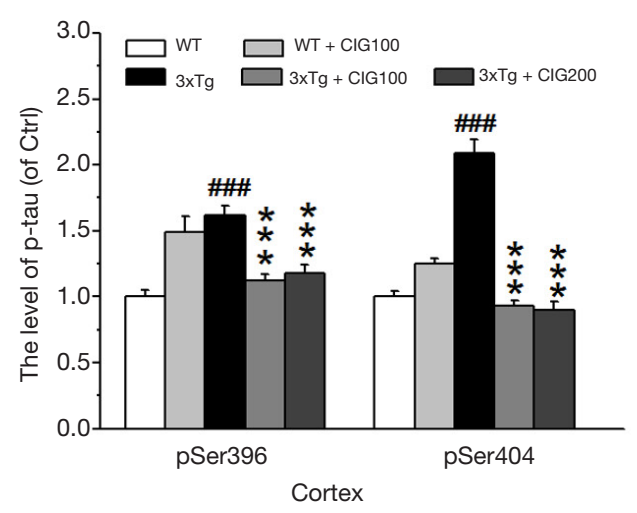

C

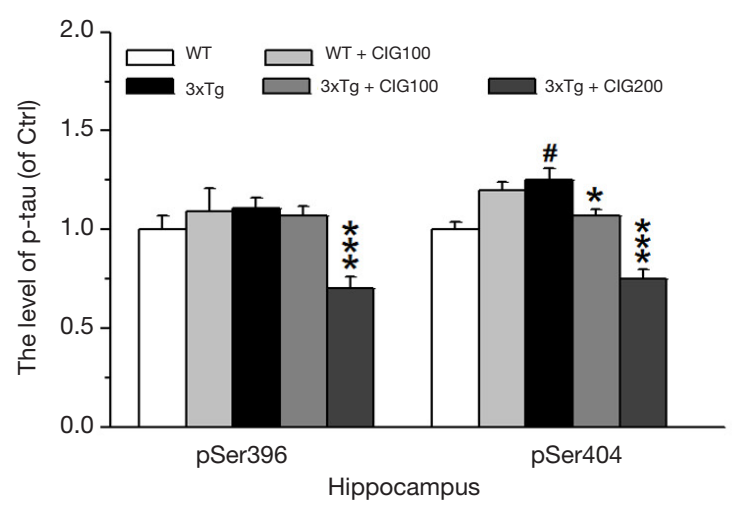

Figure 5 CIG inhibits tau hyperphosphorylation in the cerebral cortex and hippocampus of $3 \times \mathrm{Tg}$ mice (western blotting). Representative western blots of phosphorylated tau at Ser396 and Ser404, and total tau. Quantitative findings of phosphorylated tau in cerebral cortex (B) and hippocampus $(\mathrm{C})$, respectively. Internal control was $\beta$-actin. Ratio of target protein to $\beta$-actin in WT control mice was set as 1 . Data are expressed as means $\pm \mathrm{SEM} ; \mathrm{n}=4$ per group. ${ }^{\#}, \mathrm{P}<0.05,{ }^{\# \# \#,} \mathrm{P}<0.001,3 \times$ Tg group $v s$. WT group; ${ }^{*}, \mathrm{P}<0.05,{ }^{* * *}, \mathrm{P}<0.001$, CIG-treated groups vs. $3 \times \operatorname{Tg}$ group. CIG, cornel iridoid glycoside.

are presently two main ways to reduce $A \beta$ level (29). In the present study, $3 \times \mathrm{Tg}$ mice showed an increase in the expression of full-length APP and a decrease in the levels of ADAM10, IDE and NEP in the hippocampus and cerebral cortex, and an elevation in the expression of BACE- 1 in the cerebral cortex but not in the hippocampus. CIG treatment reduced the expression of APP and elevated the level of ADAM10 in the hippocampus and cerebral cortex of $3 \times \mathrm{Tg}$ mice; however, CIG did not decline BACE-1 in the cerebral cortex. These results imply that CIG may reduce the production of $\mathrm{A} \beta$ mainly via decreasing APP expression and increasing $\alpha$-secretase. We also found that CIG elevated the levels of IDE and NEP in the hippocampus and cerebral cortex of $3 \times \mathrm{Tg}$ mice, thereby might promote the degradation of $A \beta$. Our results suggest that CIG may reduce the content of $A \beta$ via both inhibiting the generation pathway and enhancing the clearance pathway of $A \beta$ in the brain of AD-like animal model.

Another neuropathological hallmark of AD is intracellular neurofibrillary tangles formed by aggregation of hyperphosphorylated tau protein. Development of tau pathology is associated with progressive neuronal loss and memory dysfunction (30). Tau is hyperphosphorylated at several Ser or Thr sites during the progression of $\mathrm{AD}$, including Ser 396 and Ser 404 (31,32). Inhibiting tau hyperphosphorylation has become a focus of current $\mathrm{AD}$ drug research. Increased tau phosphorylation was reduced by CIG at Ser 396 and Ser 404 in the cerebral cortex and hippocampus of $3 \times \mathrm{Tg}$ mice.

Tau phosphorylation is mainly regulated by protein 
A

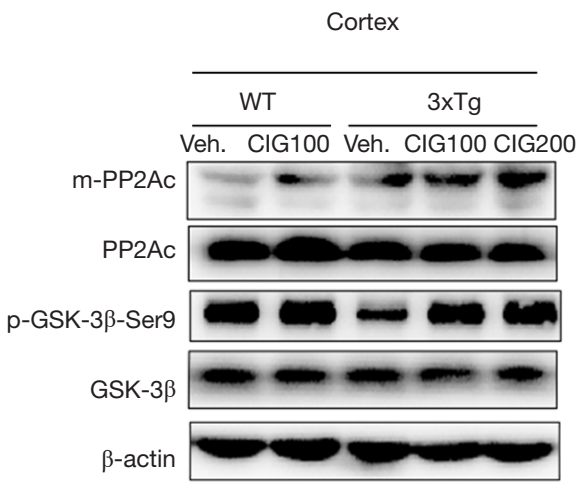

B

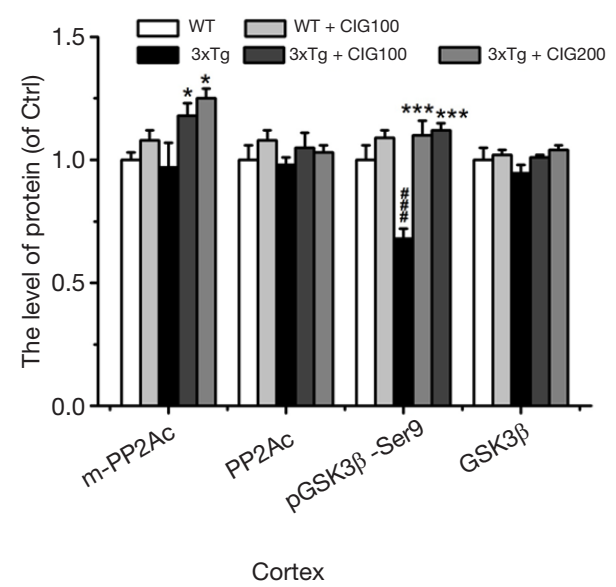

Hippocampus

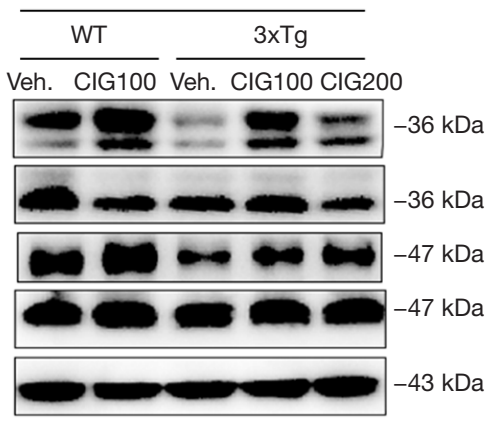

C

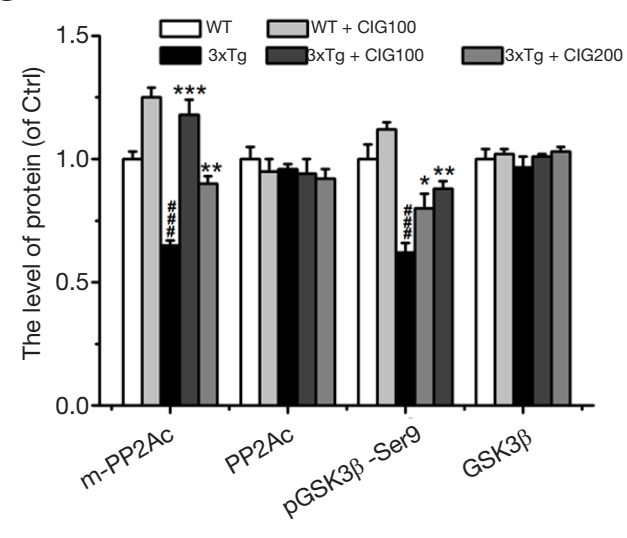

Hippocampus

Figure 6 The effects of CIG on activity-related modifications of PP2A and GSK-3 $\beta$ in the cerebral cortex and hippocampus of $3 \times$ Tg mice (western blotting). (A) Representative blots of PP2A catalytic subunit C (PP2Ac) methylated PP2Ac at Leu309 (m-PP2Ac), GSK-3 $\beta$ and phosphorylated GSK-3 $\beta$ at Ser9 (p-GSK3 $\beta$-Ser9). Quantitative findings of PP2Ac, m-PP2Ac, GSK-3 $\beta$ and p-GSK3 $\beta$-Ser9 in cerebral cortex (B) and hippocampus (C). Internal control was $\beta$-actin. Ratio of target protein to $\beta$-actin in WT control mice was set as 1 . Data are expressed as means \pm SEM; $\mathrm{n}=4$ per group. ${ }^{* \# \#}, \mathrm{P}<0.001,3 \times$ Tg group vs. WT group; ${ }^{*}, \mathrm{P}<0.05,{ }^{* *}, \mathrm{P}<0.01,{ }^{* * *}, \mathrm{P}<0.001, \mathrm{CIG}$-treated groups vs. $3 \times$ Tg group. CIG, cornel iridoid glycoside.

kinases (such as GSK-3 $\beta$ ) and protein phosphatases (such as PP2A) (6). The comparatively dominant isoform expressed in neurons, GSK-3 $\beta$, is activated in the frontal cortex and hippocampus of patients $(33,34)$. When being phosphorylated at Ser9, GSK-3 $\beta$ becomes inactive (35). The present study found that the expression of phosphorylated GSK-3 $\beta$ at Ser9 was decreased in the brain of $3 \times \mathrm{Tg}$ mice; CIG increased the phosphorylation of GSK-3 $\beta$ at Ser9 in the cerebral cortex and hippocampus of $3 \times \mathrm{Tg}$ mice, suggesting that CIG might attenuate the activity of GSK-3 $\beta$ thus reduce tau phosphorylation. The main protein phosphatase that dephosphorylates tau protein is PP2A, which consists of a scaffold (A), as well as regulatory (B), and catalytic $(\mathrm{C})$ subunits. Posttranslational modifications of its catalytic subunit $\mathrm{C}$ (PP2Ac) regulate the activity of PP2A (36), which is critical for its selective phosphatase activity toward different phosphor-protein substrates (37). PP2A shows efficient enzymatic activity when PP2Ac is methylated at Leu309 (38). Results of the present study showed that the expression of methylated PP2Ac at Leu309 was reduced in the brain of $3 \times \mathrm{Tg}$ mice; CIG increased the methylation of PP2Ac at Leu309 in the cerebral cortex and hippocampus of $3 \times \mathrm{Tg}$ mice, implying that CIG might elevate the activity of PP2A thus promote tau dephosphorylation. These results suggest that CIG may inhibit tau hyperphosphorylation through decreasing GSK-3 $\beta$ activity and increasing PP2A activity in the brain of AD-like animal model. 
A

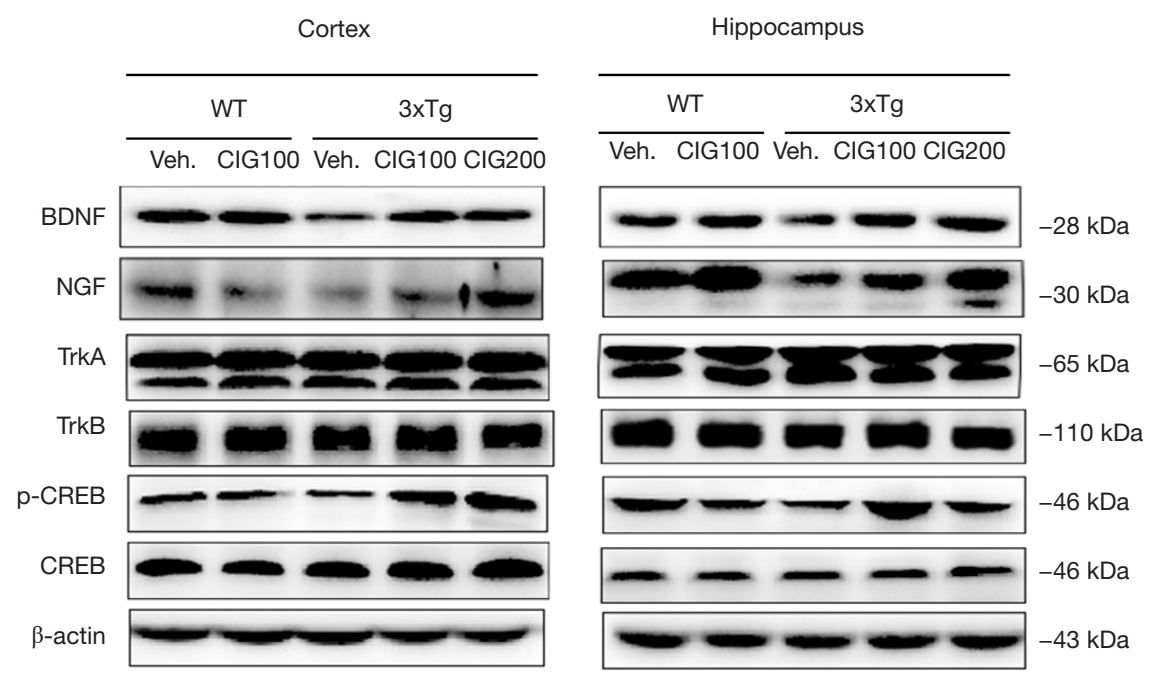

B

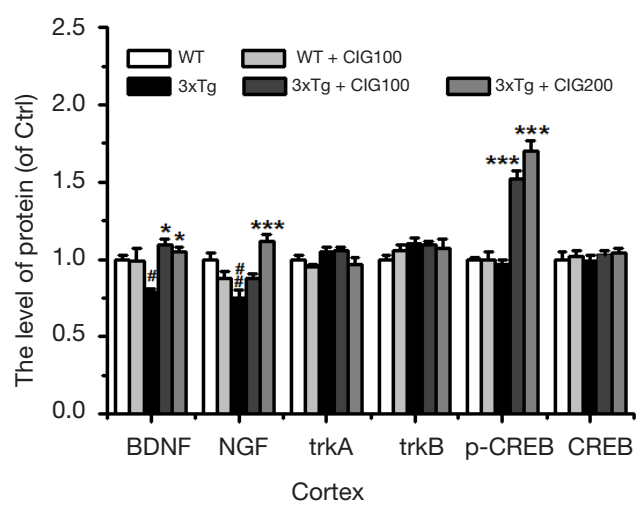

$\mathrm{C}$

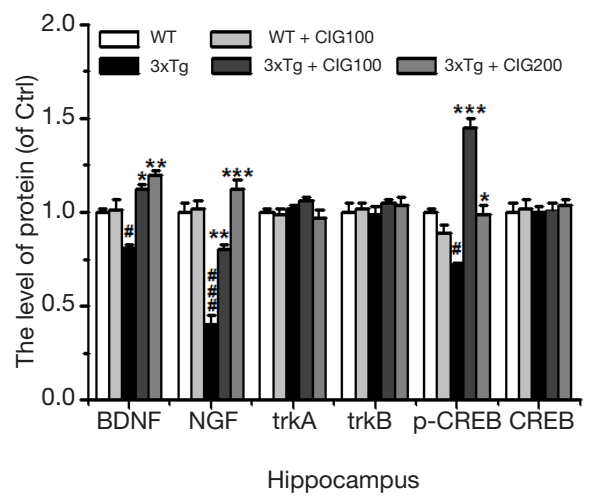

Figure 7 CIG elevates the expression of neurotrophic factors and p-CREB in the cerebral cortex and hippocampus of $3 \times \operatorname{Tg}$ mice (western blotting). (A) Representative western blots of BDNF, NGF, phosphorylated CREB (p-CREB), and CREB. Quantitative analysis of BDNF, NGF, p-CREB and CREB in cerebral cortex (B) and hippocampus (C). Internal control was $\beta$-actin. Ratio of target protein to $\beta$-actin in

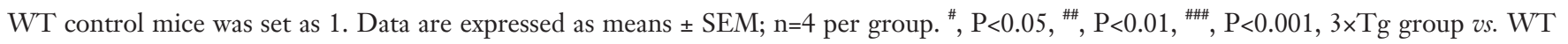
group; ${ }^{*}, \mathrm{P}<0.05,{ }^{* *}, \mathrm{P}<0.01,{ }^{* * *}, \mathrm{P}<0.001$, CIG-treated groups $v s .3 \times$ Tg group. CIG, cornel iridoid glycoside.

Neurotrophic factors are a family of secreted proteins necessary for the growth, survival and differentiation of neurons. They play essential roles in the central and peripheral nervous system by regulating diverse physiological functions of neurons, supporting axon growth and neuronal plasticity, protecting neurons from damage and apoptosis, and improving the repair of damaged neurons throughout life. Neurotrophic factors, including NGF and BDNF, are involved in the pathogenesis of $\mathrm{AD}$ (39). Studies have shown that an NGF deficiency induces cholinergic deficits, neuronal apoptosis, synaptic damage, $\mathrm{A} \beta$ deposition, neurofibrillary tangles and impaired memory
$(40,41)$. The expression of BDNF or TrkB in patients with Alzheimer, Parkinson and Huntington diseases is decreased to varying degrees (42). However, NGF and BDNF might offer a therapeutic approach based on the regenerative capacity of the brain to shift the balance from neurodegeneration to neural regeneration $(43,44)$. Brainderived neurotrophic factor shows promise for treating neurodegenerative diseases (45). We found that CIG significantly increased the low levels of NGF and BDNF expression in the cerebral cortex and hippocampus of $3 \times \mathrm{Tg}$ mice.

Many studies have shown that BDNF-TrkB signaling 
and its downstream protein, the transcription factor CREB, ameliorates deficits in neurogenesis, synaptic plasticity, and cognition (46,47), and regulates learning and memory function. Active CREB facilitates long-term potentiation (48), which is an important component of memory formation and maintenance. Somatic gene transfer of CREB improves memory impairment in aging rats (49). Several signal transduction pathways, including that of BDNF/PI3K/GSK3 $\beta$ mediate the phosphorylation of CREB, then activated phosphorylated CREB (p-CREB) associates with CREB-binding protein (CBP) to regulate the downstream expression of specific genes, thus triggering the synthesis of memory-related proteins, including BDNF (50). In our current study, we found that the expression of p-CREB was reduced in the brain of $3 \times \mathrm{Tg}$ mice, whereas CIG restored the level of p-CREB in the cerebral cortex and hippocampus. The results above imply that CIG may activate BDNF/CREB signaling pathway in the brain, and this may be one of the mechanisms by which CIG improve cognitive impairment

$\mathrm{AD}$ is a multifactorial and a highly complex process, and its pathogenesis involves multiple mechanisms (51); therefore, the single modality of "One-molecule-one-target" strategy for treatment of $\mathrm{AD}$ has failed (52). In the present study, we used APP/PS1/tau triple transgenic $(3 \times \mathrm{Tg})$ mice, and found that CIG decreased $A \beta$ content, inhibited tau hyperphosphorylation, and increased neurotrophic factors in the brain of $3 \times \mathrm{Tg}$ mice through different mechanisms. Our results suggest that CIG may be effective on multiple pathways and targets of the complex pathogenesis of $\mathrm{AD}$, and may eventually block the progression of AD. However, the limitation of this study is that the accurate targets of CIG have not been confirmed yet, further studies still need to verify them.

In conclusion, we found impaired cognitive function, increased $A \beta$ deposition and tau phosphorylation, decreased neurotrophic factors, and active CREB in the brains of18month-old APP/PS1/tau triple transgenic $(3 \times \mathrm{Tg})$ mouse models of AD. Intragastric administration of CIG for 2 months improved the cognitive impairment in these mice by decreasing amyloid plaques and $A \beta$ content via reducing $A \beta$ production and promoting $A \beta$ degradation. CIG decreased tau hyperphosphorylation by respectively attenuating and elevating GSK-3 $\beta$ and PP2A activities; CIG also increased the levels of neurotrophic factors (NGF and BDNF) and p-CREB in the cerebral cortex and hippocampus of $3 \times \mathrm{Tg}$ mice. These results suggested that CIG affects many pathways and targets involved in the complex pathogenesis of $\mathrm{AD}$, and thus might be beneficial as a new therapy for $\mathrm{AD}$.

\section{Acknowledgments}

Funding: This study was supported by the National Natural Science Foundation of China (No. 81874351, 81703729), Beijing Hospitals Authority Ascent Plan (DFL20190803); Capital Science and Technology Leading Talent Training Project (Z191100006119017), National Major Science and Technology Projects of China (No. 2015ZX09101-016), Beijing New Medical Discipline Grant (XK100270569), Beijing High-level Health and Technical Personal Plan (No. 2011-1-7, 2014-2-014).

\section{Footnote}

Conflicts of Interest: The authors have no conflicts of interest to declare.

Ethical Statement: The authors are accountable for all aspects of the work in ensuring that questions related to the accuracy or integrity of any part of the work are appropriately investigated and resolved. This study was approved by the Bioethics Committee of Xuanwu Hospital of Capital Medical University (authorization number: AEEI-2018-132).

Open Access Statement: This is an Open Access article distributed in accordance with the Creative Commons Attribution-NonCommercial-NoDerivs 4.0 International License (CC BY-NC-ND 4.0), which permits the noncommercial replication and distribution of the article with the strict proviso that no changes or edits are made and the original work is properly cited (including links to both the formal publication through the relevant DOI and the license). See: https://creativecommons.org/licenses/by-nc-nd/4.0/.

\section{References}

1. Madav Y, Wairkar S, Prabhakar B. Recent therapeutic strategies targeting beta amyloid and tauopathies in Alzheimer's disease. Brain Res Bull 2019;146:171-84.

2. Panza F, Lozupone M, Seripa D, et al. Amyloid-beta immunotherapy for alzheimer's disease - is it now a long shot? Ann Neurol 2019;85:303-15.

3. Ziegler-Waldkirch S, Meyer-Luehmann M. The role of glial cells and synapse loss in mouse models of alzheimer's 
disease. Front Cell Neurosci 2018;12:473.

4. Leuzy A, Chiotis K, Lemoine L, et al. Tau PET imaging in neurodegenerative tauopathies-still a challenge. Mol Psychiatry 2019;24:1112-34.

5. den Haan J, Morrema T, Verbraak FD, et al. Amyloidbeta and phosphorylated tau in post-mortem Alzheimer's disease retinas. Acta Neuropathol Commun 2018;6:147.

6. Ma RH, Zhang Y, Hong XY, et al. Role of microtubuleassociated protein tau phosphorylation in Alzheimer's disease. J Huazhong Univ Sci Technolog Med Sci 2017;37:307-12.

7. Selkoe DJ. Alzheimer's disease: Genes, proteins, and therapy. Physiol Rev 2001;81:741-66.

8. Zhou $\mathrm{ZD}$, Chan $\mathrm{CH}, \mathrm{Ma} \mathrm{QH}$, et al. The roles of amyloid precursor protein (APP) in neurogenesis: Implications to pathogenesis and therapy of Alzheimer disease. Cell Adh Migr 2011;5:280-92.

9. Wang YJ, Zhou HD, Zhou XF. Clearance of amyloidbeta in Alzheimer's disease: Progress, problems and perspectives. Drug Discov Today 2006;11:931-8.

10. Flaherty DB, Soria JP, Tomasiewicz HG, et al. Phosphorylation of human tau protein by microtubuleassociated kinases: GSK3 beta and cdk5 are key participants. J Neurosci Res 2000;62:463-72.

11. Gordon-Weeks PR, Fournier AE. Neuronal cytoskeleton in synaptic plasticity and regeneration. J Neurochem 2014;129:206-12.

12. Tapia-Rojas C, Cabezas-Opazo F, Deaton CA, et al. It's all about tau. Prog Neurobiol 2019;175:54-76.

13. Jiao SS, Shen LL, Zhu C, et al. Brain-derived neurotrophic factor protects against tau-related neurodegeneration of Alzheimer's disease. Transl Psychiatry 2016;6:e907.

14. Cuello AC. Editorial: The involvement of NGF in the alzheimer's pathology. Front Neurosci 2019;13:872.

15. Ma D, Zhu Y, Li Y, et al. Beneficial effects of cornel iridoid glycoside on behavioral impairment and senescence status in SAMP8 mice at different ages. Behav Brain Res 2016;312:20-9.

16. Zhao LH, Ding YX, Zhang L, et al. Cornel iridoid glycoside improves memory ability and promotes neuronal survival in fimbria-fornix transected rats. Eur J Pharmacol 2010;647:68-74.

17. Yang CC, Kuai XX, Li YL, et al. Cornel iridoid glycoside attenuates tau hyperphosphorylation by inhibition of PP2A demethylation. Evid Based Complement Alternat Med 2013;2013:108486.

18. Yang JT, Wang ZJ, Cai HY, et al. Sex differences in neuropathology and cognitive behavior in APP/PS1/tau
Triple-Transgenic mouse model of alzheimer's disease. Neurosci Bull 2018;34:736-46.

19. Yao RQ, Zhang L, Wang W, et al. Cornel iridoid glycoside promotes neurogenesis and angiogenesis and improves neurological function after focal cerebral ischemia in rats. Brain Res Bull 2009;79:69-76.

20. Antunes M, Biala G. The novel object recognition memory: Neurobiology, test procedure, and its modifications. Cogn Process 2012;13:93-110.

21. Nagele RG, D'Andrea MR, Lee H, et al. Astrocytes accumulate a beta 42 and give rise to astrocytic amyloid plaques in Alzheimer disease brains. Brain Res 2003;971:197-209.

22. Patil SP, Maki S, Khedkar SA, et al. Withanolide a and asiatic acid modulate multiple targets associated with amyloid-beta precursor protein processing and amyloidbeta protein clearance. J Nat Prod 2010;73:1196-202.

23. Jin $\mathrm{N}, \mathrm{Wu} \mathrm{Y,} \mathrm{Xu} \mathrm{W}$, et al. C-terminal truncation of GSK3 beta enhances its dephosphorylation by PP2A. Febs Lett 2017;591:1053-63.

24. Fields J, Dumaop W, Langford TD, et al. Role of neurotrophic factor alterations in the neurodegenerative process in HIV associated neurocognitive disorders. J Neuroimmune Pharmacol 2014;9:102-16.

25. Triani F, Tramutola A, Di Domenico F, et al. Biliverdin reductase-A impairment links brain insulin resistance with increased Abeta production in an animal model of aging: Implications for Alzheimer disease. Biochim Biophys Acta Mol Basis Dis 2018;1864:3181-94.

26. Sandebring A, Welander H, Winblad B, et al. The pathogenic abeta 43 is enriched in familial and sporadic Alzheimer disease. Plos One 2013;8:e55847.

27. Corbett GT, Gonzalez FJ, Pahan K. Activation of peroxisome proliferator-activated receptor alpha stimulates ADAM10-mediated proteolysis of APP. Proc Natl Acad Sci U S A 2015;112:8445-50.

28. Folch J, Petrov D, Ettcheto M, et al. Current research therapeutic strategies for alzheimer's disease treatment. Neural Plast 2016;2016:8501693.

29. Singh S, Kushwah AS, Singh R, et al. Current therapeutic strategy in Alzheimer's disease. Eur Rev Med Pharmacol Sci 2012;16:1651-64.

30. Li R, He P, Cui J, et al. Brain endogenous estrogen levels determine responses to estrogen replacement therapy via regulation of BACE1 and NEP in female Alzheimer's transgenic mice. Mol Neurobiol 2013;47:857-67.

31. Morishima-Kawashima M, Hasegawa M, Takio $\mathrm{K}$, et al. Proline-directed and non-proline- 
directed phosphorylation of PHF-tau. J Biol Chem 1995;270:823-9.

32. Neddens J, Temmel M, Flunkert S, et al. Phosphorylation of different tau sites during progression of Alzheimer's disease. Acta Neuropathol Commun 2018;6:52.

33. Hernandez F, Lucas JJ, Avila J. GSK3 and tau: Two convergence points in Alzheimer's disease. J Alzheimers Dis 2013;33 Suppl 1:S141-4.

34. Blalock EM, Geddes JW, Chen KC, et al. Incipient Alzheimer's disease: Microarray correlation analyses reveal major transcriptional and tumor suppressor responses. Proc Natl Acad Sci U S A 2004;101:2173-8.

35. Ahn YM, Seo MS, Kim SH, et al. Increased phosphorylation of Ser473-Akt, Ser9-GSK-3beta and Ser133-CREB in the rat frontal cortex after MK-801 intraperitoneal injection. Int J Neuropsychopharmacol 2005;8:607-13.

36. Chu D, Tan J, Xie S, et al. GSK-3beta is dephosphorylated by PP2A in a leu309 Methylation-Independent manner. J Alzheimers Dis 2016;49:365-75.

37. Park HJ, Lee KW, Park ES, et al. Dysregulation of protein phosphatase $2 \mathrm{~A}$ in parkinson disease and dementia with lewy bodies. Ann Clin Transl Neurol 2016;3:769-80.

38. Janssens V, Longin S, Goris J. PP2A holoenzyme assembly: In cauda venenum (the sting is in the tail). Trends Biochem Sci 2008;33:113-21.

39. Budni J, Bellettini-Santos T, Mina F, et al. The involvement of BDNF, NGF and GDNF in aging and Alzheimer's disease. Aging Dis 2015;6:331-41.

40. Isaev NK, Stelmashook EV, Genrikhs EE. Role of nerve growth factor in plasticity of forebrain cholinergic neurons. Biochemistry (Mosc) 2017;82:291-300.

41. Triaca V, Calissano P. Impairment of the nerve growth factor pathway driving amyloid accumulation in cholinergic neurons: The incipit of the Alzheimer's disease story? Neural Regen Res 2016;11:1553-6.

42. Zuccato C, Cattaneo E. Brain-derived neurotrophic factor in neurodegenerative diseases. Nat Rev Neurol 2009;5:311-22.

43. Kazim SF, Blanchard J, Dai CL, et al. Disease modifying effect of chronic oral treatment with a neurotrophic

Cite this article as: Yang C, Bao X, Zhang L, Li Y, Li L, Zhang L. Cornel iridoid glycoside ameliorates cognitive deficits in APP/PS1/tau triple transgenic mice by attenuating amyloidbeta, tau hyperphosphorylation and neurotrophic dysfunction. Ann Transl Med 2020;8(6):328. doi: 10.21037/atm.2020.02.138 peptidergic compound in a triple transgenic mouse model of Alzheimer's disease. Neurobiol Dis 2014;71:110-30.

44. Xu CJ, Wang JL, Jin WL. The emerging therapeutic role of NGF in alzheimer's disease. Neurochem Res 2016;41:1211-8.

45. Shin MK, Kim HG, Baek SH, et al. Neuropep-1 ameliorates learning and memory deficits in an Alzheimer's disease mouse model, increases brain-derived neurotrophic factor expression in the brain, and causes reduction of amyloid beta plaques. Neurobiol Aging 2014;35:990-1001.

46. Je HS, Yang F, Ji Y, et al. Role of pro-brain-derived neurotrophic factor (proBDNF) to mature BDNF conversion in activity-dependent competition at developing neuromuscular synapses. Proc Natl Acad Sci U S A 2012;109:15924-9.

47. Einoch R, Weinreb O, Mandiuk N, et al. The involvement of BDNF-CREB signaling pathways in the pharmacological mechanism of combined SSRI- antipsychotic treatment in schizophrenia. Eur Neuropsychopharmacol 2017;27:470-83.

48. Barco A, Alarcon JM, Kandel ER. Expression of constitutively active CREB protein facilitates the late phase of long-term potentiation by enhancing synaptic capture. Cell 2002;108:689-703.

49. Mouravlev A, Dunning J, Young D, et al. Somatic gene transfer of cAMP response element-binding protein attenuates memory impairment in aging rats. Proc Natl Acad Sci U S A 2006;103:4705-10.

50. Jain V, Baitharu I, Prasad D, et al. Enriched environment prevents hypobaric hypoxia induced memory impairment and neurodegeneration: Role of BDNF/PI3K/GSK3beta pathway coupled with CREB activation. Plos One 2013;8:e62235.

51. Iraji A, Firuzi O, Khoshneviszadeh M, et al. Synthesis and structure-activity relationship study of multi-target triazine derivatives as innovative candidates for treatment of Alzheimer's disease. Bioorg Chem 2018;77:223-35.

52. Sahoo AK, Dandapat J, Dash UC, et al. Features and outcomes of drugs for combination therapy as multitargets strategy to combat Alzheimer's disease. J Ethnopharmacol 2018;215:42-73. 